\title{
Fruit Intake and Changes of Cardio- Metabolic Risk Factors in People with Obesity
}

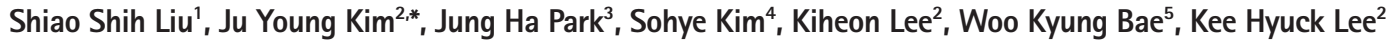 \\ Jong Soo Han ${ }^{5}$, Hyejin Lee' ${ }^{2}$, Se Young Jung ${ }^{2}$ \\ 'Department of Family Medicine, Seoul National University Hospital, Seoul, Korea \\ ${ }^{2}$ Department of Family Medicine, Seoul National University Bundang Hospital, Seongnam, Korea \\ ${ }^{3}$ Department of Family Medicine, Jeju National University Hospital, Jeju, Korea \\ ${ }^{4}$ Nutrition Care Services, Seoul National University Bundang Hospital, Seongnam, Korea \\ ${ }^{5}$ Department of Family Medicine, Health Promotion Center, Seoul National University Bundang Hospital, Seongnam, Korea
}

Background: This study aimed to explore the relationship between fruit intake, changes in fruit intake, and changes in cardiometabolic factors in people with obesity.

Methods: A total of 21,270 subjects (8,718 men, 12,552 women) aged 40 years and over, from the Korean-based Genome and Epidemiology Study, were followed up for an average of 4.4 years. Fruit intake was assessed using a food frequency questionnaire at baseline and the second follow-up. The beta coefficient and confidence intervals for changes in cardiometabolic risk factors according to fruit consumption were calculated using a linear regression model.

Results: In men, the abdominal circumference decreased with changes in fruit intake $(\mathrm{P}=0.029)$. Fruit intake and increased fruit intake in men were associated with a lower systolic blood pressure $(\mathrm{P}=0.012$ and $\mathrm{P}=0.02$, respectively) and lower triglyceride levels ( $\mathrm{P}=0.002$ and $\mathrm{P}<0.001$, respectively). In women, abdominal circumference decreased with both fruit intake and increased fruit intake $(\mathrm{P}<0.001$ and $\mathrm{P}=0.013$, respectively). Systolic blood pressure and triglycerides tended to decrease only with fruit intake $(\mathrm{P}=0.048$ and $\mathrm{P}<0.001$, respectively). Unlike in men, fasting blood glucose tended to decrease in women with both fruit intake and increased fruit intake $(\mathrm{P}=0.011$ and $\mathrm{P}=0.005$, respectively).

Conclusion: Fruit intake and increased fruit intake may have beneficial effects on cardiometabolic risk factors among individuals who are obese.

Keywords: Fruit; Obesity; Metabolic Syndrome; Epidemiology

Received: September 3, 2020, Revised: October 19, 2020, Accepted: November 7, 2020

*Corresponding Author: Ju Young Kim https://orcid.org/0000-0002-4406-2428

Tel: +82-31-787-7796, Fax: +82-31-787-4078, E-mail: kkamburi@gmail.com 


\section{INTRODUCTION}

The prevalence of obesity has increased rapidly in the past 50 years. In 2016, more than 650 million adults were reported to be obese. ${ }^{1)}$ Its prevalence among Koreans has also increased significantly from $26.0 \%$ in 1998 to $34.1 \%$ in $2017{ }^{2)}$ Obesity substantially increases the risk of type 2 diabetes mellitus; cardiovascular diseases, including myocardial infarction; stroke; osteoarthritis; obstructive sleep apnea; depression; and some types of cancer, including breast, ovarian, prostate, liver, kidney, and colon cancers. ${ }^{3,4)}$ Obesity is also an important factor related to metabolic syndrome that involves a cluster of cardiometabolic risk factors including abdominal obesity, high blood pressure, abnormal fasting glucose, and dyslipidemia. ${ }^{5-7)}$

Fruits constitute an important part of our diet, owing to their fiber, antioxidants, and micronutrient contents. ${ }^{8}$ Hence, it is recommended as part of a healthy diet. ${ }^{9)}$ Fruit consumption also has beneficial effects on decreasing the risk of several chronic diseases. ${ }^{9}$ Some studies have reported that fruit intake lowers the risk of metabolic syndrome and its components. ${ }^{10-12)}$ A meta-analysis on how fruit intake affects metabolic syndrome in a dose-response relationship reported that the risk of metabolic syndrome decreased with increased fruit intake. ${ }^{13)}$ In contrast, another study reported the two to be unrelated. ${ }^{14)}$ To date, the influence of fruit intake on metabolic syndrome remains controversial.

Many fruits are known to have high concentrations of fruit sugars and simple sugars such as glucose and fructose and are considered the main cause of increased adiposity. ${ }^{15)}$ Several studies have shown the pro-obesity effects of various types of fruits. One study has demonstrated a positive association between fruit juice consumption and adiposity in children, although this effect was observed only in children who were already obese or overweight. ${ }^{16)}$
Many epidemiological studies have evaluated the relationship between fruit consumption and cardiometabolic risk factors. However, the effect of fruit intake on cardiometabolic factors in individuals who are obese is not well known. This study aimed to explore the relationship between fruit intake or changes in fruit intake and changes in cardiometabolic factors in individuals who are obese by using data from Korean Genome and Epidemiology Study (KoGES).

\section{METHODS}

\section{Study Population}

The data of this study were from the rural-based cohort (2005-2011) and the city-based cohort (2004-2013) of the KoGES. ${ }^{17)}$ The KoGES is a cohort project conducted by the National Institute of Health and Human Services, Korea Centers for Disease Control and Prevention (currently, Korea Disease Control and Prevention Agency), to establish a scientific basis for the identification and prevention of risk factors for common chronic diseases in Korea. Since 2001, participants aged 40 years and over have been recruited from the general population, and follow-ups are ongoing.

To determine the cardiometabolic risk factors among adults who are obese, 133,427 individuals with a body mass index of less than 25 $\mathrm{kg} / \mathrm{m}^{2}$ were excluded from the total cohort population of 201,546 . Subjects who are on glucose-lowering medications or insulin treatment were also excluded. Moreover, subjects who had missing information related to the cardiometabolic parameters at baseline, those who did not complete a food frequency questionnaire (FFQ), those who were diagnosed with cancer or cardiovascular diseases such as angina and myocardial infarction at baseline, those with extraordinary energy intake $(<500 \mathrm{kcal} / \mathrm{d}$ or $>6,000 \mathrm{kcal} / \mathrm{d})$ at baseline, and those who refused

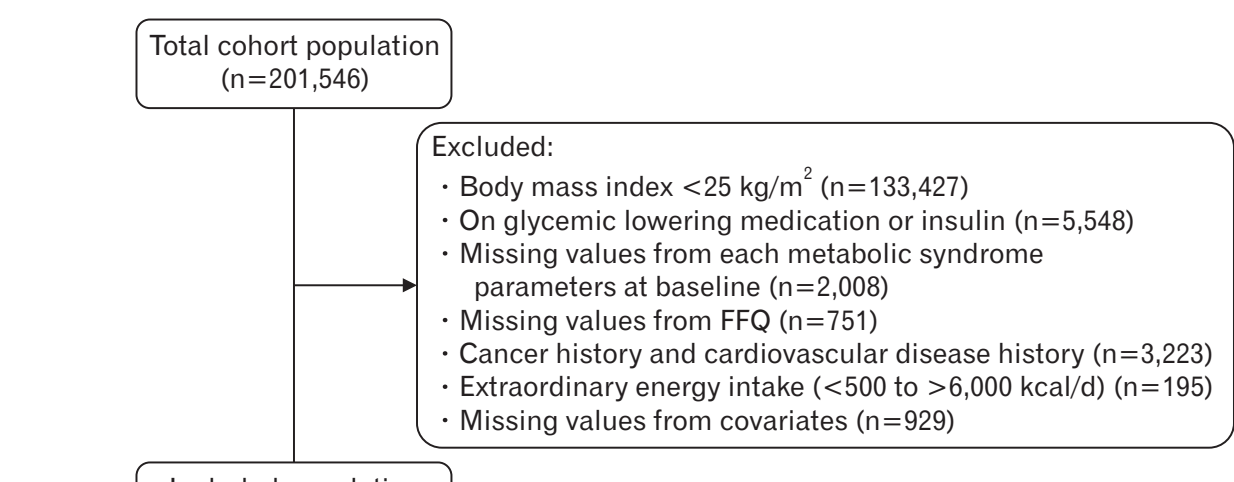

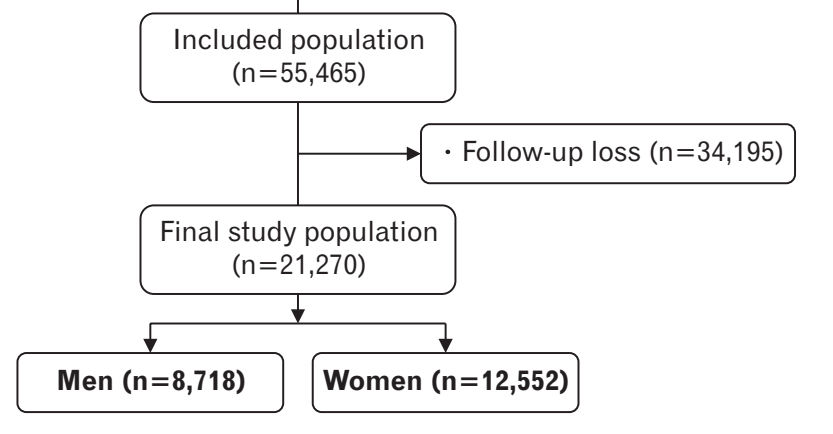

Figure 1. Flowchart of study population. FFQ, food frequency questionnaire. 
to participate in the follow-up examinations were excluded. Our final study population consisted of a total of 21,270 subjects (8,718 men and 12,552 women) with an average follow-up of 4.4 years (Figure 1). The Institutional Review Board of Bundang Seoul National University Hospital approved this study (IRB approval no., X-1910-568-906).

\section{Measurements of Cardiometabolic Factors and Socio- Demographic Factors}

Basic information and data on past medical history, medication use,and health-related behaviors were collected using self-administered questionnaires. Height, weight, and waist circumference were measured with the subjects in light clothing and correct posture. The body mass index was calculated as weight $(\mathrm{kg}) /$ height $\left(\mathrm{m}^{2}\right)$. The waist circumference was measured at the midpoint between the lowest rib and the iliac crest. Blood pressure was measured using a mercury sphygmomanometer (W. A. Baum Co. Inc., Copiague, NY, USA), with the persons in the correct posture during measurement by adjusting the height so that the feet touch the floor without twisting of the legs and the right upper arm is at the same level as the heart; furthermore, we also allowed more than 5 minutes of rest before the measurement. With the subject in a stable and correct measurement posture, the blood pressure was measured at least twice at each visit and on both arms, and the sound was measured by Korotkoff phase I and V, respectively. Blood tests were performed after fasting for at least 8 hours, and fasting blood glucose, triglyceride, and high-density lipoprotein cholesterol (HDL cholesterol) levels were assessed using an autoanalyzer (Bayer HealthCare, Berlin, Germany).

\section{Cardiometabolic Risk Factors}

We explored the parameters used to characterize metabolic syndrome. Metabolic syndrome was defined as per the National Cholesterol Education Program/Adult Treatment Panel III, namely, having three or more of the following five factors: central obesity, impaired glucose tolerance, hyperlipidemia, low HDL cholesterol, and hypertension. ${ }^{18)}$ We explored the changes in waist circumference, systolic and diastolic blood pressure, triglycerides, HDL cholesterol, and fasting blood glucose over time.

\section{Dietary Assessment}

In this study, validated semi-quantitative FFQ was used to assess total fruit intake. ${ }^{19)}$ The intake frequency, intake amount, and intake season of the past year were investigated. The intake frequency was changed daily, and the intake was converted to grams to calculate the average daily intake. The FFQ included a total of 11 fruits (strawberry, melon, watermelon, peach, banana, persimmon, tangerine, pear, apple, orange, and grape). The total energy intake and the intake of each macronutrient were also calculated as the average daily intake and corrected by calculating the grams per 1,000 kcal of total energy intake.

\section{Covariates}

Physical activity was coded as yes if the frequency of activity was more than 3 times per week with moderate intensity. Smoking status was categorized as never smoker, former smoker, or current smoker. Regarding alcohol consumption, each subject was categorized as a nondrinker, former drinker, or current drinker. Monthly family income was classified into four groups as follows: $<1$ million won (equivalent to US dollar [USD] 830), between 1 and 2 million won (equivalent to approximately USD 1,650), between 2 and 4 million won (equivalent to approximately USD 3,300), or >USD 3,300. Education level was classified as graduating from primary school, high school, or above.

\section{Statistical Analysis}

Categorical variables were presented as numbers with percentages, and continuous variables were presented as means and standard deviations.

The independent variables in this study were the amount of baseline fruit consumption and the changes in fruit consumption. The former was analyzed by baseline intake, while the latter was analyzed using the difference after subtracting baseline intake from follow-up intake. The beta coefficient and confidence intervals for changes in cardiometabolic risk factors according to fruit consumption were calculated using a linear regression model. Before applying linear regression, the following were assessed using Pearson correlations: baseline fruit intake, changes in fruit intake, and changes in cardiometabolic risk factors.

Model 1 was adjusted for age, body mass index, total energy intake, and macronutrient intake, with Model 2 additionally adjusted for smoking status, alcohol intake, and physical activity. Model 3 included socioeconomic factors, household income, and education level, in addition to the variables in Model 2. All statistical analyses were performed using STATA software ver. 16.0 (Stata Corp., College Station, TX, USA). Statistical significance was indicated by P-values less than 0.05 .

\section{RESULTS}

\section{General Characteristics}

The baseline characteristics according to sex are presented in Table 1. The prevalence of hypertension and dyslipidemia was significantly higher in men than in women $(\mathrm{P}=0.003$ and $\mathrm{P}=0.039$, respectively). In men, the percentage who exercised more than 3 times per week with moderate intensity was higher than that in women (56.9\% versus $46.1 \%, \mathrm{P}<0.001)$. Moreover, current smokers $(27.2 \%$ versus $1.8 \%$, $\mathrm{P}<0.001)$ and current drinker $(73.0 \%$ versus $28.7 \%, \mathrm{P}<0.001)$ were significantly higher in men than in women.

Baseline cardiometabolic parameters according to sex were identified. The average HDL cholesterol level was significantly higher in women than in men $(\mathrm{P}<0.001)$, and the average waist circumference, systolic blood pressure, triglyceride level, and fasting blood sugar levels were significantly higher in men than in women (all $\mathrm{P}<0.001$ ). Total energy intake was measured to be $1,888.9 \pm 541.0 \mathrm{kcal} / \mathrm{d}$ for men and $1,696.3 \pm 539.1 \mathrm{kcal} / \mathrm{d}$ for women. The total fruit intake corrected for to- 
Table 1. Baseline characteristics of participants

\begin{tabular}{|c|c|c|c|}
\hline Characteristic & Men & Women & P-value \\
\hline No. of participants & 8,718 & 12,552 & \\
\hline $\operatorname{Age}(y)$ & $54.8 \pm 8.5$ & $55.0 \pm 8.0$ & $<0.001$ \\
\hline Body mass index $\left(\mathrm{kg} / \mathrm{m}^{2}\right)$ & $27.0 \pm 1.7$ & $27.2 \pm 2.0$ & $<0.001$ \\
\hline Present of hypertension & $2,521(28.9)$ & $3,442(27.4)$ & $<0.01$ \\
\hline Present of dyslipidemia & $986(11.3)$ & $1,363(10.9)$ & $<0.05$ \\
\hline Physical activity & & & $<0.001$ \\
\hline Yes & $4,958(56.9)$ & $5,786(46.1)$ & \\
\hline No & $3,760(43.1)$ & $6,766(53.9)$ & \\
\hline Smoking & & & $<0.001$ \\
\hline Never smoker & $2,485(28.5)$ & 12,192 (97.1) & \\
\hline Former smoker & $3,860(44.3)$ & $134(1.1)$ & \\
\hline Current smoker & $2,373(27.2)$ & $226(1.8)$ & \\
\hline Alcohol use & & & $<0.001$ \\
\hline Non-drinker & $1,724(19.8)$ & $8,686(69.3)$ & \\
\hline Former drinker & $628(7.2)$ & $248(2.0)$ & \\
\hline Current drinker & 6,366 (73.0) & $3,608(28.7)$ & \\
\hline Family income (million won/mo) & & & $<0.001$ \\
\hline$<1$ & $681(9.2)$ & $1,806(18.2)$ & \\
\hline $1-2$ & $1,310(17.7)$ & $2,323(23.4)$ & \\
\hline $2-4$ & $3,259(44.1)$ & $3,951(39.7)$ & \\
\hline$>4$ & $2,134(28.9)$ & $1,862(18.7)$ & \\
\hline Education year (y) & & & $<0.001$ \\
\hline$\leq 6$ & $1,944(22.3)$ & $5,108(40.7)$ & \\
\hline$>6-12$ & $3,447(39.6)$ & $5,742(45.8)$ & \\
\hline$>12$ & $3,323(38.1)$ & $1,693(13.5)$ & \\
\hline \multicolumn{4}{|l|}{ Cardio-metabolic parameters } \\
\hline Waist circumference (cm) & $91.2 \pm 5.9$ & $86.7 \pm 6.8$ & $<0.001$ \\
\hline Systolic blood pressure (mm Hg) & $128.9 \pm 14.4$ & $125.8 \pm 15.3$ & $<0.001$ \\
\hline Diastolic blood pressure $(\mathrm{mm} \mathrm{Hg})$ & $81.3 \pm 9.7$ & $78.1 \pm 9.8$ & 0.599 \\
\hline Triglycerides $(\mathrm{mg} / \mathrm{dL})$ & $173.7 \pm 111.0$ & $135.8 \pm 82.1$ & $<0.001$ \\
\hline High-density lipoprotein-cholesterol (mg/dL) & $45.7 \pm 10.5$ & $50.9 \pm 11.6$ & $<0.001$ \\
\hline Fasting blood glucose (mg/dL) & $98.4 \pm 17.7$ & $94.2 \pm 15.8$ & $<0.001$ \\
\hline Total fruit intake $(\mathrm{g} / 1,000 \mathrm{kcl})^{*}$ & $78.4 \pm 72.0$ & $112.8 \pm 96.0$ & $<0.001$ \\
\hline Total energy intake (kcal/d) & $1888.9 \pm 541.0$ & $1696.3 \pm 539.1$ & 0.713 \\
\hline \multicolumn{4}{|l|}{ Macronutrient intake ${ }^{\dagger}$} \\
\hline Carbohydrate (g/1,000 kcal) & $178.1 \pm 17.0$ & $182.7 \pm 17.5$ & $<0.01$ \\
\hline Protein $(\mathrm{g} / 1,000 \mathrm{kcal})$ & $33.3 \pm 6.2$ & $32.9 \pm 6.6$ & $<0.001$ \\
\hline Fat $(\mathrm{g} / 1,000 \mathrm{kcal})$ & $15.7 \pm 5.9$ & $14.1 \pm 6.0$ & 0.095 \\
\hline
\end{tabular}

Values are presented as mean \pm standard deviation or number (\%). By chi-square tests or generalized linear models. P-values $<0.05$ were considered significant.

${ }^{*}$ Total fruit intake=strawberry+melon+watermelon+peach+banana+persimmon+tangerine+pear+apple+orange+grape. ${ }^{\dagger}$ Adjustment for total energy [(macronutrient/total energy intake) $\times 1,000]$.

tal energy intake per $1,000 \mathrm{kcal}$ was higher in women $(78.4 \pm 72.0$ $\mathrm{g} / 1,000 \mathrm{kcal}$ for men and $112.8 \pm 96.0 \mathrm{~g} / 1,000 \mathrm{kcal}$ for women). The total amount of carbohydrates ingested was also higher in women $(\mathrm{P}=0.002)$, while protein intake was higher in men $(\mathrm{P}<0.001)$. Fat intake was not significantly different between men and women $(\mathrm{P}=0.095)$.

\section{Relationship between Fruit Intake, Changes in Fruit Intake, and Cardiometabolic Syndrome Components}

The effect of total baseline fruit intake and increased fruit intake with respect to baseline cardiometabolic risk factors, based on sex, are presented in Tables 2 and 3, along with the beta coefficient values and confidence intervals.

In men, abdominal circumference decreased when the fruit intake was increased from baseline $(\mathrm{P}=0.002)$, even after correcting for all covariates $(\mathrm{P}=0.029)$. However, it was not related to the total fruit consumption at baseline $(\mathrm{P}=0.102)$. Both the total amount of fruit intake and increase in fruit intake were significantly associated with reduced systolic blood pressure $(\mathrm{P}=0.012$ and $\mathrm{P}=0.02$, respectively) and triglycerides ( $\mathrm{P}=0.002$ and $\mathrm{P}<0.001$, respectively). In contrast, diastolic blood pressure, HDL cholesterol, and fasting blood glucose were not associated with fruit intake in men.

In women, abdominal circumference decreased with both the amount of fruit intake and an increase in fruit intake $(\mathrm{P}<0.001$ and $\mathrm{P}=0.013$, respectively). Systolic blood pressure and triglycerides tended to decrease only when the total baseline fruit intake increased $(\mathrm{P}=0.048$ and $\mathrm{P}<0.001$, respectively). Finally, unlike in men, fasting 
Table 2. Linear regression and 95\% confidence intervals for changes of each metabolic syndrome components according to whole fruit consumption and changes of fruit consumption in men $(n=8,718)$

\begin{tabular}{|c|c|c|c|c|}
\hline Variable & Unadjusted & Model 1 & Model 2 & Model 3 \\
\hline \multicolumn{5}{|l|}{ Waist circumference (cm) } \\
\hline Amounts of fruit consumption $(\mathrm{g} / \mathrm{d})$ & $-0.02(-0.05$ to 0.02$)$ & $-0.07(-0.11$ to -0.03$)$ & $-0.05(-0.09$ to -0.00$)$ & $-0.04(-0.08$ to 0.01$)$ \\
\hline P-value & 0.369 & $<0.01$ & $<0.05$ & 0.102 \\
\hline Changes of fruit consumption $(\mathrm{g} / \mathrm{d})$ & $-0.05(-0.08$ to 0.02$)$ & $-0.05(-0.08$ to -0.02$)$ & $-0.04(-0.07$ to -0.01$)$ & $-0.04(-0.07$ to -0.00$)$ \\
\hline P-value & $<0.01$ & $<0.001$ & $<0.01$ & $<0.05$ \\
\hline \multicolumn{5}{|l|}{ Systolic blood pressure (mm Hg) } \\
\hline Amounts of fruit consumption $(\mathrm{g} / \mathrm{d})$ & $-0.03(-0.11$ to 0.05$)$ & $-0.12(-0.23$ to -0.01$)$ & $-0.14(-0.25$ to -0.03$)$ & $-0.15(-0.27$ to -0.03$)$ \\
\hline P-value & 0.513 & $<0.05$ & $<0.05$ & $<0.05$ \\
\hline Changes of fruit consumption $(\mathrm{g} / \mathrm{d})$ & $-0.02(-0.08$ to 0.05$)$ & $-0.05(-0.13$ to 0.03$)$ & $-0.07(-0.14$ to 0.01$)$ & $-0.10(-0.18$ to -0.02$)$ \\
\hline P-value & 0.633 & 0.206 & 0.095 & $<0.05$ \\
\hline \multicolumn{5}{|l|}{ Diastolic blood pressure (mm Hg) } \\
\hline Amounts of fruit consumption $(\mathrm{g} / \mathrm{d})$ & $-0.08(-0.13$ to -0.02$)$ & $-0.05(-0.12$ to 0.03$)$ & $-0.06(-0.13$ to 0.01$)$ & $-0.07(-0.15$ to 0.01$)$ \\
\hline P-value & $<0.01$ & 0.205 & 0.11 & 0.08 \\
\hline Changes of fruit consumption $(\mathrm{g} / \mathrm{d})$ & $0.01(-0.03$ to 0.06$)$ & $-0.01(-0.06$ to 0.05$)$ & $-0.02(-0.07$ to 0.04$)$ & $-0.03(-0.08$ to 0.03$)$ \\
\hline P-value & 0.581 & 0.806 & 0.528 & 0.383 \\
\hline \multicolumn{5}{|l|}{ Triglyceride (mg/dL) } \\
\hline Amounts of fruit consumption $(\mathrm{g} / \mathrm{d})$ & $-0.01(-0.01$ to -0.00$)$ & $-0.01(-0.01$ to -0.01$)$ & $-0.01(-0.01$ to -0.00$)$ & $-0.01(-0.01$ to -0.00$)$ \\
\hline P-value & $<0.001$ & $<0.001$ & $<0.01$ & $<0.01$ \\
\hline Changes of fruit consumption $(\mathrm{g} / \mathrm{d})$ & $-0.00(-0.01$ to -0.00$)$ & $-0.01(-0.01$ to -0.01$)$ & $-0.01(-0.01$ to -0.00$)$ & $-0.01(-0.01$ to -0.00$)$ \\
\hline P-value & $<0.001$ & $<0.001$ & $<0.001$ & $<0.001$ \\
\hline \multicolumn{5}{|l|}{ HDL-cholesterol (mg/dL) } \\
\hline Amounts of fruit consumption $(\mathrm{g} / \mathrm{d})$ & $0.01(-0.07$ to 0.08$)$ & $-0.01(-0.10$ to 0.09$)$ & $0.06(-0.14$ to 0.06$)$ & $-0.03(-0.14$ to 0.08$)$ \\
\hline P-value & 0.877 & 0.881 & 0.411 & 0.591 \\
\hline Changes of fruit consumption $(\mathrm{g} / \mathrm{d})$ & $0.06(-0.00$ to 0.11$)$ & $0.07(-0.00$ to 0.14$)$ & $0.04(-0.03$ to 0.11$)$ & $0.02(-0.05$ to 0.10$)$ \\
\hline P-value & 0.053 & 0.067 & 0.254 & 0.590 \\
\hline \multicolumn{5}{|l|}{ Fasting plasma glucose (mg/dL) } \\
\hline Amounts of fruit consumption $(\mathrm{g} / \mathrm{d})$ & $0.01(-0.11$ to 0.12$)$ & $-0.03(-0.18$ to 0.12$)$ & $0.06(-0.09$ to 0.21$)$ & $0.05(-0.12$ to 0.21$)$ \\
\hline P-value & 0.921 & 0.711 & 0.424 & 0.599 \\
\hline Changes of fruit consumption $(\mathrm{g} / \mathrm{d})$ & $-0.02(-0.11$ to 0.07$)$ & $-0.02(-0.12$ to 0.09$)$ & $0.02(-0.09$ to 0.13$)$ & $0.00(-0.11$ to 0.12$)$ \\
\hline P-value & 0.647 & 0.767 & 0.717 & 0.967 \\
\hline
\end{tabular}

Values are presented as odds ratio (95\% confidence interval), unless otherwise stated. P-values <0.05 were considered significant. Model 1 was adjusted for age, BMl, total energy intake, and macronutrient intake; model 2 was adjusted for age, BMI, smoking status, alcohol intake, physical activity, total energy intake, and macronutrient intake; and model 3 was adjusted for age, BMl, smoking status, alcohol intake, physical activity, total energy intake, macronutrient intake, household income, and education level. BMl, body mass index; HDL, high-density lipoprotein.

blood glucose decreased in women with baseline fruit intake and an increase in fruit intake with respect to baseline $(\mathrm{P}=0.011$ and $\mathrm{P}=0.005$, respectively). Similar to that in men, diastolic blood pressure and HDL cholesterol levels in women were not associated with fruit intake.

\section{DISCUSSION}

In this study, we found that generally favorable changes occurred when the total amount of fruit consumed or changes in fruit consumption increased among individuals who are obese. With the increase in total fruit consumption, waist circumference, systolic blood pressure, and triglycerides decreased in men and women. Unlike men, women's fasting blood glucose also showed favorable changes with an increase in fruit intake.

A meta-analysis that examined the changes in body anthropometric variables according to fruit intake showed a decrease in waist circumference with an increase in fruit intake, ${ }^{20)}$ which concurs with the results of our study. Several studies have shown that an increase in fruit intake among middle-aged adults lowers the risk of hypertension. ${ }^{21,22)}$ There are also longitudinal studies that have suggested that an increase in fruit intake is associated with a lower $\mathrm{BP}^{10,23)}$ The results of our study also showed a tendency for systolic blood pressure to decrease with an increase in fruit intake. In the case of triglycerides, other studies have shown that it is significantly lowered as the amount of fruit intake increases, as in our study. ${ }^{15}$

Regarding the association between fruit consumption and blood glucose, the effect of an increase in fruit intake on the risk of developing diabetes remains controversial. While some studies have not found a link between blood glucose and fruit intake, ${ }^{24,25)}$ others have shown that the incidence of diabetes was decreased with an increase in fruit intake. ${ }^{26)}$ In our study, fasting blood glucose was reduced with increased fruit intake as well as by changes in fruit intake, but only in women who were obese but non-diabetic. The blood glucose level did not worsen as the fruit intake increased. We considered that the fiber in fruits may help to control blood sugar. ${ }^{27)}$ The relationship between fiber and blood glucose control has been well studied, ${ }^{8,27)}$ and fiber in- 
Table 3. Linear regression and 95\% confidence intervals for changes of each metabolic syndrome components according to whole fruit consumption and changes of fruit consumption in women $(\mathrm{n}=12,552)$

\begin{tabular}{|c|c|c|c|c|}
\hline Variable & Unadjusted & Model 1 & Model 2 & Model 3 \\
\hline \multicolumn{5}{|l|}{ Waist circumference (cm) } \\
\hline Amounts of fruit consumption (g/d) & $-0.10(-0.13$ to -0.07$)$ & $-0.10(-0.13$ to -0.06$)$ & $-0.10(-0.13$ to -0.06$)$ & $-0.08(-0.11$ to -0.03$)$ \\
\hline P-value & $<0.001$ & $<0.001$ & $<0.001$ & $<0.001$ \\
\hline Changes of fruit consumption $(\mathrm{g} / \mathrm{d})$ & $-0.01(-0.03$ to 0.01$)$ & $-0.03(-0.06$ to -0.01$)$ & $-0.03(-0.05$ to -0.00$)$ & $-0.03(-0.06$ to -0.02$)$ \\
\hline P-value & 0.358 & $<0.05$ & $<0.05$ & $<0.01$ \\
\hline \multicolumn{5}{|l|}{ Systolic blood pressure (mm Hg) } \\
\hline Amounts of fruit consumption (g/d) & $-0.03(-0.09$ to 0.03$)$ & $-0.10(-0.18$ to -0.01$)$ & $-0.11(-0.20$ to -0.03$)$ & $-0.10(-0.20$ to -0.00$)$ \\
\hline P-value & 0.358 & $<0.05$ & $<0.05$ & $<0.05$ \\
\hline Changes of fruit consumption $(\mathrm{g} / \mathrm{d})$ & $-0.02(-0.06$ to 0.03$)$ & $-0.02(-0.08$ to 0.05$)$ & $-0.03(-0.09$ to 0.03$)$ & $-0.05(-0.12$ to 0.02$)$ \\
\hline P-value & 0.538 & 0.622 & 0.377 & 0.152 \\
\hline \multicolumn{5}{|l|}{ Diastolic blood pressure (mm Hg) } \\
\hline Amounts of fruit consumption (g/d) & $-0.04(-0.08$ to -0.00$)$ & $-0.07(-0.12$ to -0.01$)$ & $-0.08(-0.13$ to -0.02$)$ & $-0.06(-0.13$ to 0.00$)$ \\
\hline P-value & $<0.05$ & $<0.05$ & $<0.01$ & 0.057 \\
\hline Changes of fruit consumption $(\mathrm{g} / \mathrm{d})$ & $0.01(-0.02$ to 0.04$)$ & $-0.00(-0.04$ to 0.04$)$ & $-0.01(-0.05$ to 0.03$)$ & $-0.01(-0.05$ to 0.04$)$ \\
\hline P-value & 0.414 & 0.884 & 0.656 & 0.816 \\
\hline \multicolumn{5}{|l|}{ Triglyceride $(\mathrm{mg} / \mathrm{dL})$} \\
\hline Amounts of fruit consumption (g/d) & $-0.00(-0.01$ to -0.00$)$ & $-0.00(-0.01$ to -0.00$)$ & $-0.01(-0.01$ to -0.00$)$ & $-0.00(-0.01$ to -0.00$)$ \\
\hline P-value & $<0.001$ & $<0.001$ & $<0.001$ & $<0.01$ \\
\hline Changes of fruit consumption $(\mathrm{g} / \mathrm{d})$ & $0.00(-0.00,0.00)$ & $-0.00(-0.00$ to 0.00$)$ & $-0.00(-0.00$ to 00.00$)$ & $-0.00(-0.00$ to 0.00$)$ \\
\hline P-value & 0.150 & 0.164 & 0.264 & 0.453 \\
\hline \multicolumn{5}{|l|}{ HDL-cholesterol (mg/dL) } \\
\hline Amounts of fruit consumption (g/d) & 0.13 (0.07 to 0.18$)$ & 0.08 (0.00 to 0.16$)$ & 0.07 (0.01 to 0.15$)$ & $0.05(-0.04$ to 0.15$)$ \\
\hline P-value & $<0.001$ & $<0.05$ & 0.105 & 0.245 \\
\hline Changes of fruit consumption $(\mathrm{g} / \mathrm{d})$ & $-0.00(-0.05$ to 0.04$)$ & $0.05(-0.01$ to 0.10$)$ & $0.04(-0.02$ to 0.09$)$ & $-0.03(-0.09$ to 0.03$)$ \\
\hline P-value & 0.936 & 0.102 & 0.200 & 0.313 \\
\hline \multicolumn{5}{|l|}{ Fasting plasma glucose (mg/dL) } \\
\hline Amounts of fruit consumption $(\mathrm{g} / \mathrm{d})$ & $-0.08(-0.15$ to -0.01$)$ & $-0.09(-0.19$ to 0.01$)$ & $-0.09(-0.19$ to 0.01$)$ & $-0.15(-0.26$ to -0.03$)$ \\
\hline P-value & $<0.05$ & 0.073 & 0.077 & $<0.05$ \\
\hline Changes of fruit consumption $(\mathrm{g} / \mathrm{d})$ & $-0.03(-0.08$ to 0.03$)$ & $-0.08(-0.15$ to -0.01$)$ & $-0.08(-0.15$ to -0.01$)$ & $-0.11(-0.19$ to -0.03$)$ \\
\hline P-value & 0.333 & $<0.05$ & $<0.05$ & $<0.01$ \\
\hline
\end{tabular}

Values are presented as odds ratio ( $95 \%$ confidence interval), unless otherwise stated. P-values $<0.05$ were considered significant. Model 1 was adjusted for age, BMI, total energy intake, and macronutrient intake; model 2 was adjusted for age, BMI, smoking status, alcohol intake, physical activity, total energy intake, and macronutrient intake; and model 3 was adjusted for age, BMl, smoking status, alcohol intake, physical activity, total energy intake, macronutrient intake, household income, and education level. $\mathrm{BMI}$, body mass index; HDL, high-density lipoprotein.

take has shown definite beneficial effects in controlling blood glucose. In addition to fiber, vitamin C, polyphenols, and high levels of potassium and magnesium also affect blood sugar regulation and may contribute to the lowering of blood glucose. ${ }^{28,29)}$ The reason that the effect was only observed in women in our study may be due to the amount of mean total fruit intake in women being significantly greater than that in men; thus, there may be some threshold of fruit intake required to protect against an increase in blood glucose. Fruits contain many nutrients that may act as antioxidants, such as vitamin C, vitamin E, minerals, and phytochemicals; their dietary fiber also helps to reduce oxidative stress, lower blood pressure, and improve insulin resistance. ${ }^{8)}$ These nutrients inhibit lipogenesis and adipogenesis and activate lipolysis and adipocyte apoptosis. The mechanism is collectively referred to as the anti-obesity effect. As fruit intake increases, the antiobesity effect may have a positive influence on cardiometabolic risk factors, even in adults who are obese. ${ }^{30}$

\section{Strengths and Limitations}

Our study has several limitations. First, it is not possible to quantitatively suggest how much fruit should be consumed, as we did not express the degree of change in each risk factor according to the changes in fruit intake or fruit intake per se. Second, self-reported FFQ may lead to recall biases in the data obtained for the intake of each nutrient and fruit intake. Moreover, lifestyle factors, including exercise, have a major impact on cardiometabolic risk factors. Those who exercise intensely and maintain other healthy lifestyle habits are more likely to eat fruits. However, we did attempt to adjust for these variables in our analysis.

Our study also has several strengths. First, our cohort was representative of the Korean population; thus, the results are generalizable. Moreover, we used data from both rural and urban cohorts to reduce the regional bias. Second, using a longitudinal cohort, we were able to not only explore how the baseline fruit intake affects cardiometabolic risk factors but also the effects of changes in fruit intake on cardiometabolic risk factors. Most studies in the literature have analyzed cross- 
sectional data, and only a few studies have longitudinally analyzed the relationship between cardiometabolic risk factors and fruit intake or changes in fruit intake. Further studies are required to explore the effect of different fruit types on cardiometabolic risk factors. In conclusion, a higher amount of fruit intake as well as an increase in fruit intake may have beneficial effects on the cardiometabolic risk factors of individuals who are obese.

\section{CONFLICT OF INTEREST}

No potential conflict of interest relevant to this article was reported.

\section{ORCID}

Shiao Shih Liu: https://orcid.org/0000-0001-5188-2910 Ju Young Kim: https://orcid.org/0000-0002-4406-2428 Jung Ha Park: https://orcid.org/0000-0002-1269-333X Sohye Kim: https://orcid.org/0000-0003-0880-3580 Kiheon Lee: https://orcid.org/0000-0002-7139-2342 Woo Kyung Bae: https://orcid.org/0000-0001-6729-4128 Kee Hyuck Lee: https://orcid.org/0000-0001-6906-4887 Jong Soo Han: https://orcid.org/0000-0001-9248-9998 Hyejin Lee: https://orcid.org/0000-0001-5279-340X Se Young Jung: https://orcid.org/0000-0001-9946-8807

\section{REFERENCES}

1. World Health Organization. Controlling the global obesity epidemic [Internet]. Geneva: World Health Organization; 2021 [cited 2020 Jul 31]. Available from: https://www.who.int/activities/controlling-theglobal-obesity-epidemic.

2. Seo MH, Kim YH, Han K, Jung JH, Park YG, Lee SS, et al. Prevalence of obesity and incidence of obesity-related comorbidities in Koreans based on National Health Insurance Service health checkup data 2006-2015. J Obes Metab Syndr 2018;27:46-52.

3. Smith CJ, Perfetti TA, Hayes AW, Berry SC. Obesity as a source of endogenous compounds associated with chronic disease: a review. Toxicol Sci 2020;175:149-55.

4. Egger G, Dixon J. Beyond obesity and lifestyle: a review of 21st century chronic disease determinants. Biomed Res Int 2014;2014:731685.

5. Alshehri AM. Metabolic syndrome and cardiovascular risk. J Family Community Med 2010;17:73-8.

6. Eckel RH, Grundy SM, Zimmet PZ. The metabolic syndrome. Lancet 2005;365:1415-28.

7. Sattar N, McConnachie A, Shaper AG, Blauw GJ, Buckley BM, de Craen AJ, et al. Can metabolic syndrome usefully predict cardiovascular disease and diabetes?: outcome data from two prospective studies. Lancet 2008;371:1927-35.

8. Slavin JL, Lloyd B. Health benefits of fruits and vegetables. Adv Nutr 2012;3:506-16.

9. Wang X, Ouyang Y, Liu J, Zhu M, Zhao G, Bao W, et al. Fruit and vegetable consumption and mortality from all causes, cardiovascular disease, and cancer: systematic review and dose-response meta-analysis of prospective cohort studies. BMJ 2014;349:g4490.

10. Dauchet L, Kesse-Guyot E, Czernichow S, Bertrais S, Estaquio C, Peneau S, et al. Dietary patterns and blood pressure change over 5-y follow-up in the SU.VI.MAX cohort. Am J Clin Nutr 2007;85:1650-6.

11. Zhang Y, Zhang DZ. Associations of vegetable and fruit consumption with metabolic syndrome: a meta-analysis of observational studies. Public Health Nutr 2018;21:1693-703.

12. Lim M, Kim J. Association between fruit and vegetable consumption and risk of metabolic syndrome determined using the Korean Genome and Epidemiology Study (KoGES). Eur J Nutr 2020;59:1667-78.

13. Lee M, Lim M, Kim J. Fruit and vegetable consumption and the metabolic syndrome: a systematic review and dose-response meta-analysis. Br J Nutr 2019;122:723-33.

14. Shin JY, Kim JY, Kang HT, Han KH, Shim JY. Effect of fruits and vegetables on metabolic syndrome: a systematic review and meta-analysis of randomized controlled trials. Int J Food Sci Nutr 2015;66:416-25.

15. Yuan C, Lee HJ, Shin HJ, Stampfer MJ, Cho E. Fruit and vegetable consumption and hypertriglyceridemia: Korean National Health and Nutrition Examination Surveys (KNHANES) 2007-2009. Eur J Clin Nutr 2015;69:1193-9.

16. Faith MS, Dennison BA, Edmunds LS, Stratton HH. Fruit juice intake predicts increased adiposity gain in children from low-income families: weight status-by-environment interaction. Pediatrics 2006;118: 2066-75.

17. Kim Y, Han BG; KoGES Group. Cohort profile: the Korean Genome and Epidemiology Study (KoGES) Consortium. Int J Epidemiol 2017; 46:e20.

18. Alberti KG, Eckel RH, Grundy SM, Zimmet PZ, Cleeman JI, Donato $\mathrm{KA}$, et al. Harmonizing the metabolic syndrome: a joint interim statement of the International Diabetes Federation Task Force on Epidemiology and Prevention; National Heart, Lung, and Blood Institute; American Heart Association; World Heart Federation; International Atherosclerosis Society; and International Association for the Study of Obesity. Circulation 2009;120:1640-5.

19. Ahn Y, Kwon E, Shim JE, Park MK, Joo Y, Kimm K, et al. Validation and reproducibility of food frequency questionnaire for Korean genome epidemiologic study. Eur J Clin Nutr 2007;61:1435-41.

20. Schwingshackl L, Hoffmann G, Kalle-Uhlmann T, Arregui M, Buijsse B, Boeing H. Fruit and vegetable consumption and changes in anthropometric variables in adult populations: a systematic review and metaanalysis of prospective cohort studies. PLoS One 2015;10:e0140846.

21. Borgi L, Muraki I, Satija A, Willett WC, Rimm EB, Forman JP. Fruit and vegetable consumption and the incidence of hypertension in three prospective cohort studies. Hypertension 2016;67:288-93.

22. Wang L, Manson JE, Gaziano JM, Buring JE, Sesso HD. Fruit and vegetable intake and the risk of hypertension in middle-aged and older women. Am J Hypertens 2012;25:180-9.

23. Miura K, Greenland P, Stamler J, Liu K, Daviglus ML, Nakagawa H. Relation of vegetable, fruit, and meat intake to 7 -year blood pressure change in middle-aged men: the Chicago Western Electric Study. Am J Epidemiol 2004;159:572-80.

24. Hamer M, Chida Y. Intake of fruit, vegetables, and antioxidants and risk of type 2 diabetes: systematic review and meta-analysis. J Hypertens 2007;25:2361-9.

25. Kurotani K, Nanri A, Goto A, Mizoue T, Noda M, Kato M, et al. Vegeta- 
ble and fruit intake and risk of type 2 diabetes: Japan Public Health Center-based Prospective Study. Br J Nutr 2013;109:709-17.

26. Li M, Fan Y, Zhang X, Hou W, Tang Z. Fruit and vegetable intake and risk of type 2 diabetes mellitus: meta-analysis of prospective cohort studies. BMJ Open 2014;4:e005497.

27. Weickert MO, Pfeiffer AF. Metabolic effects of dietary fiber consumption and prevention of diabetes. J Nutr 2008;138:439-42.

28. Carter P, Gray LJ, Talbot D, Morris DH, Khunti K, Davies MJ. Fruit and vegetable intake and the association with glucose parameters: a cross- sectional analysis of the Let's Prevent Diabetes Study. Eur J Clin Nutr 2013;67:12-7.

29. Dibaba DT, Xun P, Song Y, Rosanoff A, Shechter M, He K. The effect of magnesium supplementation on blood pressure in individuals with insulin resistance, prediabetes, or noncommunicable chronic diseases: a meta-analysis of randomized controlled trials. Am J Clin Nutr 2017;106:921-9.

30. Sharma SP, Chung HJ, Kim HJ, Hong ST. Paradoxical effects of fruit on obesity. Nutrients 2016;8:633. 